\title{
Do Possible Worlds Compromise God's Beauty? A reply to Mark lan Thomas Robson
}

JON ROBSON

Department of Philosophy, University of Nottingham, University Park, Nottingham, NG7 2RD, UK

jonvrobson@googlemail.com

\begin{abstract}
In a recent article Mark Ian Thomas Robson argues that there is a clear contradiction between the view that possible worlds are a part of God's nature and the theologically pivotal, but philosophically neglected, claim that God is perfectly beautiful. In this paper I show that Robson's argument depends on several key assumptions which he fails to justify and as such that there is reason to doubt the soundness of his argument. I also demonstrate that if Robson's argument were sound then this would be a problem for all classical theists and not just those who hold the possible worlds view.
\end{abstract}

\section{Introduction}

The view that possible worlds are, in some sense, part of God's nature has a rather impressive pedigree $^{1}$. It has been discussed with approval, or at least sympathy, by a number of prominent philosophers and theologians from Leibniz to Alvin Plantinga ${ }^{2}$. Mark lan Thomas Robson, however, has recently proposed a new challenge to this view ${ }^{3}$. According to Robson there is 'a clear contradiction'4 between the view that possible worlds are a part of God's nature and the theologically pivotal, but philosophically neglected, claim that God is perfectly beautiful. I am sympathetic to Robson's methodological claim that many recent studies into the divine nature have lost sight of the divine beauty amid the endless discussions about power and knowledge ${ }^{5}$. However, I will argue that Robson 
fails to provide sufficient support for the particular claim he makes concerning beauty and that his argument gives us no reason to deny that possible worlds are part of the divine nature.

In the next section I present a brief outline of Robson's argument for the claim that the possible worlds view is incompatible with God's perfect beauty. In the following section I argue that Robson's argument depends on certain questionable principles concerning beauty, or at least perfect beauty, which Robson fails to adequately motivate. I conclude that as things stand we should be agnostic about the truth of these principles. I then go on to highlight another important flaw in Robson's argument; its over-reliance on a metaphorical understanding of possible worlds as stories. I argue that once we put these metaphorical trappings aside we can easily reject an analogy which is vital to the success of Robson's argument. In the final section I present an argument which demonstrates that Robson's own position, and that of any classical theist, commits them to denying the soundness of an argument exactly parallel to the one Robson proposes. I conclude, then, that Robson has failed to establish that his argument is sound and that if it turns out to be so then this is a problem for all classical theists and not just those who hold the possible worlds view.

\section{The Divine Storyteller}

In his article Robson argues for the incompatibility of God's perfect beauty and the existence of possible worlds. An important question to ask, then, is what exactly is meant by 'possible worlds' here. Although there has been much discussion of possible worlds in the philosophical literature there is no clear consensus as to whether there are such things or, if so, what kind of entity they are. At times Robson frames his argument as an objection to possible worlds views of all stripes-but for the most part he focuses, as I will below, on a specific type of possible world view which I will refer to as Theological Idealism about Possible Worlds $\left(\right.$ TIPW) ${ }^{6}$. TIPW views differ with respect to a number of issues, but all ascribe the following two features to the possible words they postulate. Firstly, possible worlds are, in some respect which I will make no attempt to fully specify, part of God's nature. Robson's argument is clearly focused on possible worlds views of this kind, and he only briefly discusses the status of 'worlds which are outside of God"'. He grants, for reasons that will become clear below, that such worlds appear to be compatible with God's perfect beauty but rejects them because, as others have 
argued at length elsewhere ${ }^{8}$, the existence of such (necessarily existing) objects outside of God's nature undermines God's aseity. Although this claim is controversial evaluating it properly would take us too far from the central focus of this paper so I will not pursue it here.

Secondly, the possible worlds view in question is one which 'rejects extreme realism, but which takes possible worlds seriously...that treats possible worlds as more than a convenient myth or a notational shortcut, but less than universes that resemble our own' ${ }^{9}$. Possible worlds on this view are to be identified with certain abstract objects or sets of such objects. They are not, as David Lewis would have it, concrete entities. According to Lewis other possible worlds 'are of a kind with this world of ours ${ }^{10}$, they are maximal collections of spatio-temporally connected things. Worries about the compatibility of Lewisian modal realism and theism have been discussed at length elsewhere ${ }^{11}$ and a view according to which Lewisian worlds are part of God's nature would, to say the least, be difficult to square with classical theism. Nor is it the case that possible worlds talk is, as some anti-realist accounts would have it, merely a convenient way of speaking, a convenient myth or a useful heuristic. Robson's arguments target the existence of possible worlds rather than the utility of possible worlds talk.

The remainder of this paper, then, will focus on the TIPW view. According to TIPW possible worlds are, as many contemporary metaphysicians would have it, identical to, or constructed out of, propositions, states of affairs or similar ${ }^{12}$. Where TIPW differs from standard possible worlds accounts is in claiming that these worlds are somehow contained within God, as part of his divine nature. This summary of TIPW is, of course, extremely sketchy and leaves a great many questions unanswered ${ }^{13}$. For present purposes, though, it will be useful to leave the TIPW position under discussion as generic as possible and so I will refrain from giving any flesh to this bare bones account. Robson intends his argument to serve as a refutation of all TIPW views and I intend my defence to be a defence of the overall spirit of TIPW views rather than any specific TIPW theory.

Robson's argument against TIPW centres around a parable. In this tale a pilgrim journeys to the home of a saintly person famed for her beauty, a beauty said to immeasurably surpass the beauty of any other; 'she is the all beautiful and the beautiful beyond all. She is forever so, unvaryingly, unchangeably $\mathrm{so}^{\prime 14}$. This beauty is not merely one of outward appearance but rather encompasses every aspect of her nature and being. As a philosopher Robson's pilgrim is keen to know the thoughts of the Beautiful Saint, 
which again she has been told are of the most exalted beauty, and the saint is keen to share her thoughts. She begins to tell a variety of stories, stories of 'such sheer ingenuity, originality, style and beauty $^{\prime 15}$ that Robson's pilgrim is complete transfixed by their beauty. All the more so upon learning that these beautiful stories spring wholly from her own thoughts and that she owes not even the slightest debt to any other author. So far so good. However, these are not the only stories in the saint's repertoire and after a while she moves on to other, somewhat less wholesome, tales. These narratives present excruciatingly detailed accounts of all manner of horrors; the rape and murder of a child, the exploits of an intergalactic Nazi empire 'that takes never-ending, sadistic delight in killing the innocent' and narratives 'so perverse that no mere human mind would have been able to originate such filth'16. Again the Beautiful Saint (now beginning to look as ill named as the Holy Roman Empire) is not just relaying these tales, they are not reports she has heard from others or cathartic retellings of horrors she has witnessed. These stories, as much as those which first delighted the pilgrim, spring entirely from her own mind; she is the sole source and originator of these stories which have always existed within her as part of her very nature.

Of course the Beautiful Saint represents God and her stories play the role of different possible worlds, all of which are, on the TIPW view, a part of God's nature. The argument from analogy, then, should be clear. The Beautiful Saint is ill named; her thoughts, as revealed by her stories, are not supremely beautiful but rather a disturbing mix of the sublimely beautiful and the horrifically ugly (and, of course, everything in-between). As such neither the saint's thoughts, nor the saint herself, can be considered perfectly beautiful. And since on the TIPW view God is in an analogous position, those who accept the TIPW view are committed to denying God's perfect beauty. Such a denial, though, is incompatible with a major tenet of classical theism which, let us assume, all parties in the debate are committed to upholding. As such we must reject TIPW.

I am happy to grant, on the basis of the ample evidence Robson presents ${ }^{17}$, that the perfect beauty view is a non-negotiable aspect of classical theism. In order to save TIPW, then, I need to show that it is not incompatible with the perfect beauty view, or at least that Robson has not shown it to be so. It is this second task which will be my focus for the remainder of this paper. 


\section{The Mereology of Beauty}

We can paraphrase a key part of Robson's central argument as follows:

1. On the TIPW view some of the possible worlds which are part of God's nature are horrifically ugly

2. Therefore TIPW entails that God is not perfectly beautiful

In the next section I will argue that Robson does not offer adequate justification for the first of these claims. For now, though, I want to look at whether the first claim really entails the second, and ask what relationship there is between the beauty (or ugliness) of an object's parts and the beauty of the object itself. Such questions, concerning what we may call the 'mereology of beauty', are ones we must address if we are to properly evaluate Robson's argument. Is there some principle which would allow us to move, as Robson does, from claims like 1 to claims like 2 ?

One possibility is that a part which is not beautiful, or at least a part which is actively ugly, will always prevent the whole object from being beautiful. So:

B1: For any object $x$ and any proper part of that object $p$, if $p$ is ugly then $x$ is not beautiful.

If $\mathrm{B} 1$ is true then the move Robson makes clearly succeeds. Just as clearly, though, B1 is not true and I am sure that Robson had no such principle in mind. Many objects are beautiful in spite of such imperfections; Leonard Cohen's oeuvre as a whole is exceedingly beautiful despite some rather ugly songs on the album Death of a Ladies' Man, Willem Drost's Bathsheba with King David's Letter is still a beautiful painting despite a key part of the work, its presentation of its subject, instantiating a certain moral ugliness ${ }^{18}$ and Sarajevo is still a beautiful city despite some of its buildings (such as its once great National Library) being reduced to a state of ugliness by damage from recent conflicts. Clearly, then, this principle is a non-starter. However, Robson's claims concern not mere beauty but perfect beauty, and perhaps a principle similar to B1 but restricted to instances of perfect beauty will be more successful. After all Sarajevo is not perfectly beautiful and one key barrier to its achieving this distinction is its war ravaged architecture. This view chimes well with what Robson writes in his article; and he is keen to insist that God cannot be perfectly beautiful if any part of God is, in any respect, ugly. He asserts, for instance, that 'Any ugliness, no matter how minuscule, will sully the purity of the divine beauty' ${ }^{19}$. So it seems the principle he should appeal to is something like: 
B2: For any object $x$ and any proper part of that object $p$, if $p$ is ugly then $x$ is not perfectly beautiful

B2 initially seems highly plausible, as the Sarajevo example above was intended to show. Indeed one might think that the claim that a perfectly beautiful object cannot have a part which is ugly is something close to a tautology. However, I think that the truth of B2 is, in on reflection, not so clear as it might initially appear. In order to see why consider the following principle which may be appealed to in order to support B2:

B3: For any object $x$ and any proper part of that object $p$, if $p$ is ugly then removing $p$ would make $x$ more beautiful (or at least less ugly).

'Removing' here is to be understood very broadly so as to include not merely cases where the offending part is simply extracted but also cases in which it is left in place but made more beautiful or where it is extracted and replaced by some appropriate and suitably beautiful part. If B3 were merely concerned with simple extraction it would clearly be false, extracting a single ugly stone from a beautiful archway may cause the whole edifice to collapse, but taken in this broad sense the principle has a great deal of intuitive appeal and shares with B2 the ring of a truism. However, even this initially very plausible version of B3 can be shown to be false. Consider, for example, the ballet the Rite of Spring. The ballet itself is very beautiful but contains sections, in Stravinsky's complex and dissonant music as well as Nijinsky's often deliberately awkward and ungainly choreography, which taken by themselves would be very ugly. Yet, an attempt to remove these sections, or replace them with some sanitized alternative would miss the point of the work entirely and rob it of its, admittedly complex and somewhat nonstandard, beauty. Or, to use Robson's own example, the Easter narrative as a whole would be less beautiful if we removed certain elements of it (most obviously the crucifixion) which are, in themselves, far from beautiful ${ }^{20}$. Without such elements the Easter story would no longer possess, as Robson himself admits, an important kind of 'unsentimental beauty, one that looks evil in the face, but eventually defeats $i^{\prime 21}$ and without this special kind of beauty (which requires that there be some evil or ugliness to be looked in the face) the Easter narrative would surely be drained of much of its beauty and power. If B3 is false, though, and removing an ugly part from an object may reduce, rather than enhance, its beauty, then we have some reason to doubt B2 as well. Perhaps the ugly worlds which the TIPWer postulates will add to, rather than detract from, the beauty of the divine nature as a whole. 
Robson pre-emptively responds to attempts to apply this kind of strategy against his argument in the following passage:

we cannot make the rapist's possible actions beautiful, even by trying to make these possible actions part of some grander scheme. The rapist's possible actions are ugly in themselves. God's stories of what possible rapists might do must carefully represent each part of the rapist's actions. How can these kinds of story be made beautiful $?^{22}$

This response, though, is beside the point for a number of reasons. Firstly, of course, we are not discussing (as the first part of the quote appears to suggest) the beauty or ugliness of the rapist's possible actions themselves; I am happy to stipulate that these actions, had they existed, would be horrifically and unspeakably ugly. Thankfully, though, such merely possible actions do not themselves exist according to TIPW (as they would, albeit non-actually, according to Lewisian modal realism ${ }^{23}$ ); only, as the second part of the quote reminds us, representations of them. Further the question at issue is not whether these representations themselves can be beautiful ${ }^{24}$ but whether, granted that these representations are themselves ugly, they can pay a role in making the whole of which they are a part (the whole here being God himself rather than, as Robson sometimes suggests ${ }^{25}$, the set of all possible worlds) more beautiful. I am happy, then, to grant Robson's claim that 'we cannot fit horror into a pattern which makes the horror itself beautiful' ${ }^{26}$. Again, to use the Easter example, I would not want to claim that the parts of the story representing Christ's beatings and brutal death are themselves beautiful; merely that they contribute to the beauty of the overall redemptive narrative. Robson give us no reason to believe that unspeakably ugly worlds could not play the same role in determining the overall beauty of the divine nature, and as such the TIPWer is not compelled to accept $B 2^{27}$.

It could be objected that Robson's focus is not merely being perfectly beautiful in some sense, but being 'utterly and completely beautiful' ${ }^{28}$ in the sense of having no part which is not also perfectly beautiful. Of course Robson is free to stipulate that this is what he means by 'perfect beauty', but failing to be perfectly beautiful in this stipulative sense would do nothing to refute an individual's claim to be the God of classical theism. In particular we might worry that the preceding discussion raises serious problems for construing God's perfect beauty in this way. As the examples above show placing something which is, in and of itself, very ugly in certain relations to a greater whole can, in a surprising variety of ways, give rise to a strange kind of beauty. A beauty that is often wonderfully exquisite (as it is in the examples discussed above); so much so that it does not strike me as implausible to claim that this 
kind of beauty must be present in anything which would legitimately lay claim to the title of perfect beauty. If, though, this special kind of beauty is as important as I suggest and, as Robson would have it, God's every part is beautiful then it may well be that God's beauty is no longer unsurpassable. A being like God but with the added perfection found in this curious and wonderful type of beauty may well be more beautiful, all things considered, than God and as such, in one important respect, greater than God. Such a possibility is, of course, anathema to the classical theist.

Everything I have said in the previous paragraph is, I will freely admit, purely speculative. Ideally I would at this stage be able to give a detailed account of how exactly the representations of extreme ugliness Robson discusses contribute to, and enhance, the overall beauty of God. Sadly, however, I am unable to do so. I have nothing approaching a theory as to how this could occur. Fortunately, the current dialectic does not require that I provide such an account. I am not claiming that God would be perfectly beautiful if TIPW were true or even that it is possible for something to be perfectly beautiful and yet have a part that is, in itself, extremely ugly. I doubt that our grasp of the concept of perfect beauty ${ }^{29}$, or of the intricacies of God's nature, is anywhere near sufficient to ground such confident modal claims. Rather I maintain that Robson has provided no reason for us to accept that such things are not possible. And since Robson's argument rests on the claim that a perfectly beautiful TIPW God is demonstrably not possible; that it is 'a clear contradiction ${ }^{30}$ to assert the existence of such a being, then we can see that arguing for agnosticism on this issue is all that is required to show that, in the absence of a persuasive argument for B2, Robson has failed to demonstrate his conclusion ${ }^{31}$.

This agnosticism would, of course, not be legitimate if Robson had provided such arguments. However, with the exception of the paragraph quoted above, which I have already argued fails to provide support for his case, Robson offers no argument in favour of B2 or a relevantly similar principle $^{32}$. For the most part his arguments, as we will see in the next section, focus on establishing that some TIPW possible worlds are horrifically ugly, taking it for granted that if this were the case then they would 'sully the purity of the divine beauty' ${ }^{33}$.

\section{Stories and 'stories'}


In the previous section I considered the question of whether something which is perfectly beautiful could have a part which is extremely ugly and concluded that while Robson's argument depends on denying this claim he has not provided sufficient argumentative support for this denial. In this section I will argue that that, even if we accept a principle like B2, we need not think that TIPW entails that God must be less than perfectly beautiful. This is because Robson has not established that representations of ugliness, even extreme ugliness, must themselves be ugly. This kind of worry has not escaped Robson's notice, and the first objection he considers to his own argument is the claim that, while the events represented by the Beautiful Saint's stories are horrifically ugly, the stories themselves are not $^{34}$. After all, representations of ugly things need not be ugly; Michelangelo's St. Peter's Pietà, Billie Holiday's Strange Fruit and Mantegna's St. Sebastian as well as his Crucifixion ${ }^{35}$ are all beautiful representations of ugly things.

Robson considers two versions of the objection that though the saint's stories represent ugliness they are not themselves ugly. Firstly, that these stories themselves are not properly evaluable in terms of beauty, secondly, that the stories are evaluable in this way and that they are beautiful. In response to the first criticism Robson rightly argues that stories themselves, and not just the events those stories describe, are the kind of thing that we can, and do, properly evaluate in terms of beauty ${ }^{36}$. Merely granting that some stories are evaluable in terms of beauty, though, does not establish that all stories are evaluable in this way, and in particular it does not show that the Beautiful Saint's stories are. Given Robson's descriptions of some of the saint's stories, though, I think it is natural to consider them as proper objects of aesthetic evaluation and as such I am happy to grant that they can be evaluated in this way. In response to the second point Robson argues that while some representations of ugliness (such as those I mentioned above) can be made beautiful via the judicious application of technical skill, stylistic flourishes and the like, such transformation has its limits and that no amount of artistic skill could render stories of sadistic space-Nazis beautiful. Further, even if they could, possible worlds are not the kind of thing which can have such stylistic flourishes. TIPW possible worlds tell it how it is, or rather could have been, in excruciating detail; there 'can be no extraneous, technical flourishes on God's part, no blurred, impressionistic representations ${ }^{37}$. Again these claims seem plausible and I am willing to grant, for the sake of argument at least, that they are correct.

The upshot of the above discussion, then, is that I am happy to accept Robson's claim that some of the stories which the Beautiful Saint tells are themselves evaluable in terms of beauty and ugliness, 
and that Robson's pilgrim is right to judge some of them to be horrifically ugly. The problem for Robson's argument arises when we attempt to move from conclusions about the Beautiful Saint and her stories to considering what these tell us about God and TIPW worlds. The answer I will claim is that they tell us very little. There are important disanalogies between the Beautiful Saint and God, and between stories and possible worlds, which completely undercut the force of Robson's argument from analogy.

The reason for Robson's choice of analogy is not difficult to see. There is a strong tendency to picture possible worlds, especially TIPW worlds, as a collection of books in some divine library, and Robson explicitly employs this metaphor at times ${ }^{38}$. Such metaphors are often harmless and can serve as useful discursive and pedagogical tools. It is important, however, not to get carried away by these instructive metaphors. God is not really a storyteller, and possible worlds are not, at least in any conventional sense, stories. To highlight the problems that such metaphors can give rise to consider Robson's reply to the hypothetical TIPWers objection that mere possibilities are not, in themselves, aesthetically evaluable, just as our merely possible actions are not legitimately subject to moral praise and blame: 'We might accept that mere possibilities cannot be evil or good, but we do say of stories that they are beautiful or ugly'. ${ }^{39}$ As I have said above, the second part of this claim is certainly correct; we are accustomed (and rightly so) to evaluating stories aesthetically. The objection, though, and the first part of Robson's reply, concern not stories but possibilities. To reply to the TIPWer Robson needs the claim that the relevant possibilities would themselves be ugly. Stories and possibilities are entities of quite different kinds and establishing a point about the former will not, without further argument, establish anything about the latter.

Nor is this a mere pedantic point of classification. It is not difficult to see that, once we put aside our metaphors, TIPW Possible worlds and stories actually have very little in common. Admittedly they both fall into the category of things which David Lewis terms 'corpora' 40 that is bodies 'of representations, emanating from a more or less unified source...and in which we have some more or less systematic interest ${ }^{41}$. Stories clearly belong to this category and since according to TIPW possibilities emanate from a single individual, God, it appears that they will also qualify. Corpora are a rather broad church, though, and we should not imagine that we can make much claim to similarity between two kinds of entity merely because they both happen to be members, especially since, as we 
will now see, there are a number of key differences between stories, and narratives more generally, on one hand and possible worlds on the other.

Robson claims that possible worlds, at least those like his Nazi-empire world, 'seem to constitute a story, a narrative ${ }^{\prime 42}$. To see why such appearances are misleading, consider the following disanalogy.

Narratives are typically selective; choosing to represent a specific limited set of events, usually events concerning the actions of 'individual people or small numbers of people acting in consort or in competition or both ${ }^{43}$, and presenting these within 'rich but bounded relations of consequence ${ }^{44}$. Possible worlds by contrast are maximally non-selective. Take Robson's Nazi empire world. It is easy to picture this world as being a piece of alternative history writing gone wrong, a snuff tale filled with gleefully descriptive accounts of the imaginative and gruesome tortures the intergalactic Reich imposes upon its numerous victims. And the relevant TIPW world would contain a representation analogous, though perhaps not very closely analogous, to a detailed description of these events, but it would also contain excruciatingly detailed representations of everything else that would obtain were such a world to be actualized. And I mean everything; every thought that ever crossed the mind of a fourteenth century peasant, every squashed beetle, the exact trajectories of every piece of dust, the history of stellar activity in the Andromeda galaxy, an infinitely long list of mathematical truths. Focusing on these endless details is important; it is easy, and not unreasonable, to see the Beautiful Saint as in some way morally perverse given that she chooses to spend her limited story telling time focusing on detailed descriptions of the horrors the space-Nazis inflict. If you are going to be selective, why select that? God, though, makes no such selections. Possible worlds are standardly conceived of as being maximal or complete, meaning that each of them must represent every possibility as either obtaining or failing to obtain $^{45}$; you don't get less selective than that.

This lack of selectivity is very far from being the only disanalogy. Consider the following; TIPW worlds are not artefacts, they have no narrator, they are not told in any particular style (primarily because they are not told at all), very many of them (in fact infinitely many) lack any reference to the actions of persons or to any relations of consequence (causal or otherwise), and they have neither theme nor unity of subject matter ${ }^{46}$. Given how different possible worlds are from stories, then, we can 
see why establishing that some of the Beautiful Saint's stories are horribly ugly does nothing to establish that some possible worlds are ugly.

Let us look at TIPW possible worlds themselves, then, and assume, for simplicity and rather arbitrarily, that the following account is correct. Propositions are abstract entities which are somehow in a way I will make no attempt to explicate - a part of God's nature, and each proposition represents some fact or state of affairs as obtaining (or failing to obtain). All these propositions exist eternally and necessarily, but since they are aspects of God's nature this poses no threat to God's sovereignty or aseity. Any maximally consistent set of these propositions will be a possible world. Of these worlds we can select one that represents the most disgusting and depraved state of affairs possible ${ }^{47}$. The unspeakable ugliness and depravity which would have obtained had this world been actual are doubtless, thankfully, beyond our capacity to even guess at. However, to reiterate, these horrors (darkly fascinating as they may be) are also irrelevant. The only relevant question is this; is the possible world (the set of propositions) itself beautiful, ugly or neither?

The honest answer to this question is that I do not know. I have no idea how to go about settling the question of whether an abstract entity such as a proposition, or a set of propositions, is itself ugly ${ }^{48}$. Again, though, the structure of the current dialectic does not require that I offer any such resolution. To establish his claim of a 'clear contradiction' between TIPW and God's being perfectly beautiful Robson needs to show that such abstracta must be ugly and he has failed to do so. Once we put aside the metaphorical construal of possible worlds as stories, Robson no longer has any argument to support his claim that such a contradiction exists. Robson could, of course, insist that were the states of affairs these propositions represent to become actual they would be horrifically ugly, and even that any story centring on some of the most horrific events represented by these possible worlds must of necessity be ugly. The TIPWer, though, can merely accept these claims as common ground; neither of them provides any challenge to their modal or theological position.

It could be objected that the TIPW view I have chosen here prejudices the issue somewhat and that there are other, at least prima facie, consistent TIPW accounts which are much closer to being narratives of the kind Robson considers. Perhaps possible worlds are, in some sense, literally maximal narratives which God somehow recounts (perhaps only silently to himself) ${ }^{49}$. This may well be so but Robson's 
claim is that TIPW worlds, as such, are incompatible with God's perfect beauty not merely that some internally consistent accounts of such worlds would be incompatible with it. As such even if a coherent picture along the lines suggested above could be sketched this would not vindicate Robson's argument. It is worth stressing here just how strong the claim Robson is making is. There are a great many extant, and even more merely possible, accounts of the nature of possible worlds which could be given a TIPW spin. To prove his case Robson needs to give us good reason to believe that TIPW possible worlds on all of these accounts must themselves be ugly. By contrast to counter his argument the TIPWer need only, as I have attempted above, show that there are some interpretations of their view according to which we have no clear reason to judge that possible worlds are themselves ugly.

\section{A Parting Tu Quoque}

In the previous two sections I have argued that Robson fails to establish his conclusion that TIPW is incompatible with God's perfect beauty. I have shown that Robson's argument depends on two key assumptions for which he has failed to provide sufficient motivation; firstly, that if any part of an object is extremely ugly then the object itself must be less than perfectly beautiful, and secondly that representations of extreme ugliness of the kind TIPW postulates must themselves be ugly. I have not, however, shown that Robson's argument is unsound, only that in failing to demonstrate the truth of these claim he has failed to establish its soundness. I have not even shown that the classical theist ought to judge his argument to be unsound, rather than, say, remaining agnostic about its soundness. In this section I will attempt the second of these tasks and argue that anyone who is committed to upholding classical theism (including, I assume, Robson himself) ought to reject at least one of his two assumptions and as such judge Robson's argument to be unsound.

Central to my argument is the claim that it is, or ought to be, common ground among classical theists that God's thoughts, in some respect, represent horrific ugliness. What form exactly, or even approximately, such representations take is doubtless a matter for legitimate controversy, but that such representations exist should not be. For God to be omniscient, as classical theists are committed to affirming, he must have beliefs or at least some relevantly similar representational state ${ }^{50}$. Further, God's omniscience will entail that he has an exhaustive set of beliefs representing the state of the 13 
universe in its entirety. Such beliefs therefore will have to represent some extreme instances of ugliness since murder and rape, to use two of Robson's examples, are sadly not mere unactualized possibilities. So, allowing Robson's two assumptions concerning beauty which I have criticised above, we apparently get the result that at least some of God's beliefs are themselves ugly and therefore that God himself is less than perfectly beautiful. It seems, then, that once we accept these assumptions we arrive at a position incompatible with classical theism irrespective of any commitment to TIPW.

Robson considers possible tu quoques similar to the one I have presented and offers two responses. Firstly, that while the actual world contains horrors, about which God has extensive beliefs, the possible worlds TIPW theorists postulate represent extremes of ugliness next to which even these pale in comparison. There are 'whole worlds of sadism, whole worlds of rape, whole worlds of holocausts'. ${ }^{51}$ Secondly, that there is a key difference between the belief case and the TIPW case concerning the source of the representations, he has 'no problem with a God who looks outwardly at the actual rapist and murderer and knows their possibilities, their capacities, their desires, their thoughts...Such a God sees ugliness (and moral imperfection) outside of Himself'. ${ }^{2}$ His problem is only with a God, like the one postulated by TIPW, who is the source of such representation and possesses them as part of his very nature. I must confess that I find both of Robson's suggestions here rather baffling. If, as Robson would have it, representations of extreme ugliness must themselves be ugly and 'any ugliness, no matter how minuscule, will sully the purity of the divine beauty'53 then God's beliefs concerning actual rapists and murders must surely compromise his claim to perfect beauty. If such representations were of even more extreme ugliness, or had their origin in God's own nature, then this may make a bad situation worse and push God even further beneath the standard required for perfect beauty ${ }^{54}$ but given the overall structure of Robson's argument I see no explanation for why he has 'no problem' with the claim that a god with externally caused representation of actual ugliness can nevertheless be perfectly beautiful. Such worries need not detain us, however, since I can reformulate my tu quoque in such a way as to render the status of Robson's two objections irrelevant. In order to do so I will appeal to another form of mental representation: desire.

Let us consider God's status prior to creation ${ }^{55}$. At this point God will, of course, have many representations in his mind, but none of these will have originated in looking outward at creation, for the simple reason that there will be no creation to look outward at. Let us further assume that, as 14 
Robson would have it, God's representations do not include any TIPW possible worlds and further, as Robson also claims, that God has no de re representations of any of those creatures which he will one day create ${ }^{56}$. God cannot, on this picture, form any beliefs about an individual prior to their coming into existence; he may have general beliefs about the kind of individuals he will create but he has no specific beliefs about such individuals (much as it seems plausible to say both that I can right now believe that any future child of mine will have blond hair and that I cannot believe of any specific future child ${ }^{57}$ that it will be my child and that it will have blond hair). Now, let us ask of this God, does he have any desires about whether there should be 'a galactic empire that takes never-ending, sadistic delight in killing the innocent ${ }^{58}$ ? I personally take the answer here to be quite obvious - we should believe that he has desires in this respect and that he desires that such an empire not come to pass - but let us consider what could be said in objection to this response. I will take it for granted that no-one will want to say that God has a positive desire in favour of such an empire existing, so the only plausible avenue of escape will lie in arguing that God lacks any desires concerning whether such empires come about.

Firstly, it could be objected that God has no desires. The God of classical theism is complete unto himself; he requires nothing and as such desires nothing. This response may hold water given a narrow sense of 'desire' according to which one can only desire that which one presently lacks. However, I intend 'desire' here to serve as 'an all-purpose term for any first order pro attitude' ${ }^{59}$. As such for a being to have desires in this sense would be in no way incompatible with their lacking nothing. And I trust that it is clear that the God of classical theism is one who will have pro-attitudes towards certain things (love, mercy and justice, for example ${ }^{60}$ ).

So, then, the objector must claim that while God has some desires, this specific desire is one which, prior to creation at least, he does not possess. Certainly God will not adopt a neutral stance towards such empires arising, but perhaps we could argue that he takes no stance whatsoever because he has no attitudes at all concerning such empires. Although God now desires that there be no such empire, this desire only arose once actual evils crept into God's creation which caused God to have beliefs about fallen human beings and the various kinds of ugliness they were able to bring about; at which point he, of course, started to desire that such ugliness (ceteris paribus) be avoided. Such an account, however, would make a mockery of divine providence. Surely any god able to make even a minimally successful plan for creating a universe must be aware prior to implementing that plan of at least the general kinds of problem such an endeavour could encounter, such as sadistic galactic empires, 
and desire to avoid such pitfalls. It may be that, as Peter Van Inwagen suggests ${ }^{61}$, a perfectly good God would create free beings whose actions he cannot fully predict in the expectation that the good resulting from this (their freely choosing to love, and be eternally united with, him) would outweigh the evil that such a strategy risked producing ('the horrors of the very long but, in the most literal sense temporary period of divine - human estrangement ${ }^{\prime 62}$ ). To create such creatures without so much as an inkling as to the kind of risks involved, though, would surely be irresponsible in the extreme.

Having established, then, that God has such desires and that, given the situation I have outlined, they are not caused by anything external, it should not be difficult to see how my argument proceeds from here. Desires are representational states and as such we must concede (i) that God has representations of exactly the kind of ugliness Robson wants to avoid by eliminating TIPW worlds and (ii) that such representations are part of his eternal nature. Of course, as previously stipulated, such representations are not of any specific galactic empire; but that is irrelevant. I can see no reason for thinking that a representation of the galactic Nazi empire doing unspeakable things thus and so must be ugly whereas one of some evil galactic empire or another doing unspeakable things thus and so may not be. As such we can see that a successful tu quoque can be produced against Robson irrespective of whether his objections to the original tu quoque argument are successful.

Before concluding I wish to briefly consider one response which could be offered to both Robson's original argument as well as my tu quoque version. This response goes as follows: the alleged possible worlds Robson describes are of such a kind that, given their depravity and ugliness, the God of classical theism would never actualize them (or even allow them to come about). However, since such a God is a necessary being this means that it is also necessary that such worlds are not actualized and as such they are not, after all, genuinely possible. Further, in response to my tu quoque, we can argue that since such states of affairs being actualized is impossible it would be irrational to have any desires concerning them ${ }^{63}$ and as such a perfect being would have no such desires.

Robson considers such an argument and responds that 'possible worlds are meant to be, in most possible-world semantics, the ground of our declarative statements' and that when discussing his horrifically ugly worlds we 'seem to be talking of something ${ }^{64}$. Such intuitions may be some guide to 16 
modality (though, of course, even this is controversial ${ }^{65}$ ) but they certainly aren't fool proof; for a long while naive set theory seemed perfectly consistent to a great many very clever people and when we talk about a 'set of all sets which are not members of themselves' we seem to be talking about something. Further, some theists may already be willing to bite this modal bullet for different reasons. Consider Theodore Guleserian's challenge from the 'Modal Problem of Evil' ${ }^{66}$. According to Guleserian, 'there are possible worlds of such a character that a morally perfect being ought not to actualize them ${ }^{67}$ and as such it cannot be a necessary truth, as classical theism would have it, that there exists a being who is omnipotent, omniscient, and morally perfect. For if such a being existed then worlds such as these, for example worlds filled only with excruciating and uninterrupted animal suffering, would not be possible. One response, though far from the only one ${ }^{68}$, to such a challenge is to deny that such worlds are, in fact, possible. God, the respondent argues, necessarily exists and is essentially omnipotent, omniscient and morally perfect as such it is not possible that he would actualize such worlds (or even allow them to be actualised). While such a response would preserve the classical theistic view it also, as Guleserian points out at length ${ }^{69}$, goes dramatically against a number of entrenched modal intuitions.

However, even assuming we are willing, for independent reasons, to allow that our modal intuitions are gravely mistake a strategy like the one I discuss above still has its costs. In particular we might worry that it is implausible to think that God cannot represent such impossibilities when it at least seems to be the case that we human beings $\operatorname{can}^{70}$ (it appears, for example, that we are able to understand a story in which a neo-Nazi group travels back in time and changes history to establish the intergalactic Nazi empire Robson describes). Having highlighted these potential costs, though, I will leave it to the reader to judge whether they are worth paying. I personally doubt this is the case, especially given the other options for escaping Robson's argument surveyed in the last two sections, but I will not argue for this here.

Robson and the TIPW theorist both want to retain classical theism. Further they should agree that classical theism entails that God is perfectly beautiful and, as I have argued, they are both committed (assuming they do not wish to make the counter-intuitive modal claims considered in the last few paragraphs) to the claim that God's nature contains representations of unspeakable ugliness. Given their common position they are both committed to denying one, or both, of the following: (i) representations of extreme ugliness must themselves be ugly; (ii) any object containing parts which are ugly must itself 17 
be less than perfectly beautiful. I have argued that we need not be particularly reticent to reject either of these claims, but if I am wrong about this then Robson will have provided an argument, not against the TIPWers specific conception of God, but against classical theism in general. ${ }^{71}$

\section{References}

CAMERON, ROSS P. (2009) 'God Exists at Every (Modal Realist) World a Reply to Sheehy', Religious Studies, 45, 95100.

CURRIE, GREGORY (2010) Narratives and Narrators (Oxford: Oxford University Press).

DIVERS, JOHN (2002) Possible Worlds (London: Routledge).

EFIRD, DAVID (manuscript) 'Theological Idealism about Possible Worlds'.

FORREST, PETER (1986) 'Ways Worlds Could Be', Australasian Journal of Philosophy, 64, 15-24.

GARCIA, LAURA (1984) 'A response to the modal problem of evil', Faith and Philosophy, 4, 375-358.

GAUT, BERYS (2007) Art, Emotion and Ethics (Oxford: Oxford University Press).

GULESERIAN, THEODORE (1983) 'God and Possible Worlds: The Modal Problem of Evil', Nous, 17, 221-238.

JOHNSTON, MARK (1989) 'Dispositional Theories of Value', Proceedings of the Aristotelian Society, 63, 139-74.

LEIBNIZ, G. W. (1710/1951) Theodicy: Essays on the Goodness of God, the Freedom of Man and the Origin of Evil (London: Routledge \& Kegan Paul).

LEWIS, DAVID (1982) 'Logic for Equivocators', Nous, 16, 431-41.

(1986) On the Plurality of Worlds, (Oxford: Blackwell).

PLANTINGA, ALVIN (1974) The Nature of Necessity (Oxford: Oxford University Press).

(2003) Does God have a Nature? (Milwaukee: Marquette University Press).

PSEUDO-DIONYSIUS (1978) Pseudo-Dionysius: The Complete Works (London: Classics of Western Spirituality).

ROBSON, MARK IAN THOMAS (2011) 'Possible Worlds and the Beauty of God', Religious Studies, 47, 479-492.

SHEEHY, PAUL (2006) 'Theism and Modal Realism', Religious Studies, 42, 315-328.

(2009) 'Reply to Cameron', Religious Studies, 45, 101-104.

SHERRY, PATRICK (2002) Spirit and Beauty (London: SCM Press).

SCRUTON, ROGER (1981) 'Photography and Representation', Critical Enquiry, 7, 577-603.

SORENSEN, ROY (2002) 'The Art of the Impossible', in J. Hawthorne \& T. Gendler (eds.) Conceivability and Possibility (Oxford: Oxford University Press), 337-368. 
STALNAKER, ROBERT C. (1976) 'Possible Worlds', Nous, 10, 65-75.

TIDMAN, PAUL (1993) 'The epistemology of evil possibilities', Faith and Philosophy, 10, 181-197.

VAN INWAGEN, P. (1998) 'Modal Epistemology', Philosophical Studies, 92, 67-84.

(2006) The Problem of Evil (Oxford: Oxford University Press).

\section{Notes}

${ }^{1}$ Of course the claim that God literally has parts is anathema to many classical theists. In what follows I will for the most part adopt, as Robson does, the practice of speaking as if God has parts but this is not to be taken as an endorsement of the view.

${ }^{2}$ See e.g. Leibniz (1710) and Plantinga (2003).

${ }^{3}$ In Robson (2011).

${ }^{4}$ Ibid. 479.

${ }^{5}$ Ibid. 489.

${ }^{6}$ The name is taken from David Efird (manuscript).

${ }^{7}$ Robson (2011), 488.

${ }^{8}$ See e.g. Plantinga (2003), 1-10.

${ }^{9}$ Stalnaker (1976), 75. I am grateful to an anonymous referee for drawing my attention to this passage.

${ }^{10}$ Lewis (1986), 2.

${ }^{11}$ See e.g. Sheehy $(2006,2009)$ and Cameron (2009).

${ }^{12}$ For examples of this kind of view see Stalnaker (1976), Plantinga (1974) and Forrest (1986). For a detailed discussion and evaluation of different possible worlds theories see Divers (2002).

${ }^{13}$ For attempts to flesh out TIPW see Efird (manuscript), Leibniz (1710) and Plantinga (2003), 142-146.

${ }^{14}$ Robson (2011), 480 quoting Sherry (2002), 56 (Sherry himself is quoting, with slight adaptations, from PseudoDionysius (1978), 76-77).

${ }^{15}$ Robson (2011), 480.

${ }^{16}$ Ibid. 481. All the Saint's stories tell of events that are morally deplorable as well as ugly but, as Robson explicitly acknowledges, there will also be possible worlds which represent ugly, but morally neutral, events (ibid. n.12).

${ }^{17}$ Ibid. 479-481.

${ }^{18}$ For an excellent discussion of this case see Gaut (2007), 14-25. 
${ }^{19}$ Robson (2011), 483.

${ }^{20}$ Ibid. 485

${ }^{21}$ Ibid.

22 Ibid.

${ }^{23}$ This point is owed to an anonymous referee for the journal.

${ }^{24}$ Though in the next section I will argue that we have no reason to think that they cannot be.

${ }^{25}$ Ibid.

${ }^{26}$ Ibid. n.26.

${ }^{27}$ Against such a move Robson claims that 'It does not seem to me that we can integrate these ugly, possible worlds together to make some kind of beautiful whole' but provides no clear argument to support this claim, merely asserting that the possible worlds in question are 'individual' and do not form part of 'some aggrandizing, beautiful vision' (ibid. 485).

28 Ibid. 479.

${ }^{29}$ As I said, I am very sympathetic to Robson's (ibid. 489) claim that recent philosophy of religion has focused too heavily on developing a proper understanding of omnipotence and omniscience at the expense of neglecting other divine attributes such as perfect beauty. Perhaps if there had been the level of sustained interest in the nature of perfect beauty that there has been in omniscience and omnipotence then we would have a much clearer idea of what such an attribute entails.

30 Ibid. 479.

${ }^{31}$ Such agnosticism seems even more attractive when we remember that, for most classical theists, talk of God having parts will be, strictly speaking, false. If this is so then our understanding of what God's nature is like in itself will most likely be even more limited than our ability to understand it using the familiar metaphors of parts and wholes.

${ }^{32}$ He does provide one argument (ibid. 485) for the claim that the set of all possible worlds cannot be integrated to 'make some kind of beautiful whole'. However, I will not discuss this argument since it appears to take for granted the kind of principle I have questioned in this section and presuppose that if some parts of an object are ugly then the whole cannot be perfectly beautiful.

33 Ibid. 483.

${ }^{34}$ Ibid. 482.

${ }^{35}$ See Scruton (1981), 591-92 for a seminal discussion of such cases.

${ }^{36}$ Robson (2011), 482.

${ }^{37}$ Ibid. 483.

${ }^{38}$ In e.g. ibid 482 and 485.

${ }^{39}$ Ibid. 482. 
${ }^{40}$ Lewis (1982) (quoted in Currie (2010), 8).

${ }^{41}$ Currie (2010), 8.

${ }^{42}$ Robson (2011) n.17.

${ }^{43}$ Currie (2010), 36.

${ }^{44}$ Ibid. 8.

${ }^{45}$ See Plantinga (1974), 44-45.

${ }^{46}$ I have taken these typical features of narrative from various passages in Currie (2010) (especially 7-9 and 33-39). Currie prefers to speak in terms of corpora possessing 'degrees of narrativity' (ibid. 35) rather than being straightforwardly narrative or non-narrative. In Currie's terms, then, we should say that the key difference is that stories like the ones which the Beautiful Saint tells have a very high degree of narrativity whereas TIPW worlds have, at best, a minimal degree of narrativity.

${ }^{47}$ Or if multiple worlds are equally eligible for this dubious honour, then select one such world.

${ }^{48}$ Or at least no general policy for doing so. I do not mean to deny that there are some types of abstract object, mathematical theorems for example, which we are accustomed to evaluating aesthetically (on the basis of simplicity, elegance and so forth).

${ }^{49}$ I thank an anonymous referee from the journal for this suggestion.

${ }^{50}$ I disagree with Robson's suggestion that while God has belief-like states attributing beliefs, as such, to God is anthropomorphic ((2011), 487). I am, however, sympathetic to his claim that God's knowledge is in many ways unlike our own, for instance it is not 'parcelled up into units' (ibid).

${ }^{51}$ Ibid. 484.

${ }^{52}$ Ibid.

${ }^{53}$ Ibid. 483.

${ }^{54}$ Though since Robson explicitly claims that God can see what the possibilities, capacities etc. of actual entities are (ibid. 484) even this much seems difficult to maintain. After all it was de re possible of the actual third Reich that they achieve the kind of intergalactic dominance Robson describes.

55 I will assume for the purposes of this argument that God is omni-temporal rather than atemporal (though a relevantly similar argument could be presented in atemporal terms). I do not mean to commit myself to the former view but spelling things out in these terms strikes me as appropriate since Robson appears to conceive of God as temporally located. He claims (Ibid. 484), that on the TIPW view, in contrast to his own preferred understanding, God would have knowledge of the rapist's possible actions even before the creation of the world and expresses considerable sympathy for open theism (Ibid. 485).

${ }^{56}$ Ibid. n.1.

${ }^{57}$ Either because future individuals do not exist (in even the atemporal sense) or because, even though they do I am unable to refer to them (perhaps because future individuals do not bear the appropriate causal relations to me).

${ }^{58}$ Ibid. 481.

21 
${ }^{59}$ Johnston (1989), 159.

${ }^{60}$ See, among many other texts, Micah 3:6 and Isaiah 61:8. Nor does having such pro-attitudes depend on construing God as within time; an atemporal God may be incapable of having desires in the narrow sense, since desires of this kind may (per impossibile) require God to wish for some change in his atemporal nature, but there is no such barrier to an atemporal God having pro attitudes of some kind.

${ }^{61}$ What follows is an extremely simplified version of the story presented in Van Inwagen (2006), 85-90. It is important to note that Van Inwagen (ibid. 66) presents this account not as true but only as one which 'Given that God exists...might well be true'.

62 Ibid. 90.

${ }^{63}$ For an argument to this effect see Lewis (1986), 126-127.

${ }^{64}$ Robson (2011), 489.

${ }^{65}$ See Van Inwagen (1998).

${ }^{66}$ Guleserian (1983). I thank an anonymous referee for the journal for bringing this debate to my attention.

${ }^{67}$ Ibid. 222.

${ }^{68}$ For some responses see Garcia (1984) and Tidman (1993).

${ }^{69}$ Guleserian (1983), passim.

${ }^{70}$ On whether, and in what ways, we can represent impossibilities see Sorensen (2002) (Sorensen has recently paid out on the wager he proposes in the article).

${ }^{71}$ I am grateful to Dani Adams, Carl Baker, Alice Kay, and an anonymous referee for the journal for their useful comments on earlier drafts of this paper. Work on this paper was undertaken during my time as postdoctoral fellow on the AHRC funded project 'Method in Philosophical Aesthetics: The Challenge from the Sciences'. The support of the AHRC is gratefully acknowledged. 